\title{
PENGARUH KOMPENSASI DAN MOTIVASI TERHADAP KINERJA KARYAWAN PADA PT XYZ KARAWANG
}

\section{Kevin Fewa Morando, Edi Suswardji Nugroho dan Solehudin}

Universitas Singaperbangsa Karawang, Jawa Barat, Indonesia

Email: 1910632020021@student.unsika.ac.id, edisus.nugroho@fe.unsika.ac.id dan solehudin@unsika.ac.id

\section{Abstract}

The purpose of this study was to determine the effect of compensation and motivation on the performance of employees of PT Xyz Karawang. The research was conducted by distributing questionnaires, while the research method used simple random sampling for the sampling technique. The results of the t test show that the tcount for the compensation variable (X1) is 2.832 and the tcount for the motivation variable (X2) is 6.167. From the two tcount, it shows that it is bigger than table, which is 1.65882. The hypothesis which states that compensation and motivation have a partially positive effect on employee performance at PT Xyz Karawang. Where as from the results of the F test, $F$ count $>F$ table or 55.860> 3.08 or the significance level (sig) $0.000<0.05$ so that the hypothesis that states compensation and motivation together has an effect on employee performance at PT Xyz Karawang and the coefficient of determination shows that compensation and work motivation contributed $51.1 \%$ to employee performance at PT XYZ Karawang, the remaining $48.9 \%$ were other factors which were not examined in this study.

Keywords: compensation; motivation; employee performance

\begin{abstract}
Abstrak
Tujuan dari penelitian ini adalah untuk mengetahui pengaruh kompensasi dan motivasi terhadap kinerja karyawan PT Xyz Karawang. Penelitian dilakukan dengan cara menyebar kuesioner, sedangkan metode penelitian menggunakan simple random sampling untuk teknik pengambilan sampelnya. Hasil uji $\mathrm{t}$ menunjukan bahwa besarnya $t_{\text {hitung }}$ untuk variabel kompensasi $\left(\mathrm{X}_{1}\right)$ sebesar 2,832 dan nilai thitung untuk variabel motivasi $\left(\mathrm{X}_{2}\right)$ adalah 6,167. Dari kedua thitung tersebut menunjukkan lebih besar dari $t_{\text {tabel }}$ yaitu 1,65882. Demikian juga hipotesis yang menyatakan kompensasi dan motivasi berpengaruh positif secara parsial terhadap kinerja karyawan pada PT Xyz Karawang. Sedangkan dari hasil uji F, Fhitung $>F_{\text {tabel }}$ atau 55,860 > 3,08 atau tingkat signifikansi (sig) 0,000 $<0,05$ sehingga hipotesis yang menyatakan kompensasi dan motivasi secara bersama-sama berpengaruh terhadap kinerja karyawan pada PT Xyz Karawang dan koefisien determinasi menunjukkan bahwa kompensasi dan motivasi kerja berkontribusi 51,1\% terhadap Kinerja Karyawan di PT Xyz Karawang, sisanya sebesar 48,9\% merupakan faktorfaktor lain yang tidak diteliti dalam penelitian ini.
\end{abstract}


Kevin Fewa Morando, Edi Suswardji Nugroho dan Solehudin

Kata kunci: kompensasi; motivasi; kinerja karyawan.

Coresponden Author

Email: 1910632020021@ @student.unsika.ac.id Artikel dengan akses terbuka dibawah lisensi

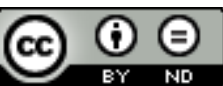

\section{Pendahuluan}

Dalam dunia bisnis persaingan yang ada saat ini, perusahaan dituntut menciptakan kinerja karyawan yang tinggi untuk melakukan pengembangan bisnis. Ada beberapa faktor yang mempengaruhi keberhasilan sutau perusahaan, faktor yang penting salah satunya adalah sumber daya manusia, karena merupakan pelaku dari seluruh proses perencanaan sampai evaluasi pada perusahaan tersebut. Tercapainya tujuan suatu perusahaan tidak hanya tergantung pada alat modern saja tetapi tergantung terhadap manusia juga yang melaksanakan pekerjaan atau tugas tersebut. Setiap organisasi atau perusahaan selalu berusaha memperbaiki dan meningkatkan kinerja karyawan agar tercapainya visi dan misi dari perusahaan tersebut.

Persaingan bisnis yang membangun akan membuat perusahaan untuk memasukkan isu sumber daya manusia ke dalam rencana pengembangan perusahaan. Perusahaan tidak hanya perlu memiliki produktivitas tinggi, tetapi juga harus menunjukkan keunggulan dalam kemampuan untuk menghasilkan barang dan jasa yang bermutu, beraneka ragam sesuai dengan kebutuhan pelanggan, disertai dengan kemudahan dan kenyamanan serta ketepatan waktu. Daya saing perusahaan akan sangat ditentukan oleh kapabilitas sumber daya manusia yang dimilikinya. Potensi sumber daya manusia yang dimiliki untuk memanfaatkan ilmu pengetahuan dan teknologi, akan menjadi sumber keunggulan yang sangat penting bagi perusahaan.

Sumber daya manusia yang profesional akan menjadi subyek utama dalam upaya untuk menghasilkan barang dan jasa atau layanan yang berkualitas tinggi dan kompetitif. Ini berlaku pada organisasi bisnis yang berorientasi laba maupun organisasi nirlaba, termasuk lembaga pemerintah. Pada akhirnya, jika kondisi ini dapat diwujudkan, maka kesejahteraan karyawan sebagai individu, kesejahteraan organisasi, dan kesejahteraan masyarakat akan dapat direalisasikan pula. Oleh karena itu organisasi atau badan usaha harus lebih menekankan pada efektivitas dan efisiensi pengelolaan sumber daya manusia sehingga tujuan awal pendiriannya dapat tercapai.

Salah satu faktor yang dapat mensejahterakan karyawan yaitu kompensasi yang diberikan kepada karyawan, kompensasi dari unsur perjanjian psikologis antara perusahaan dengan karyawan memiliki peranan yang sangat penting karena pada satu sisi dapat berpengaruh langsung terhadap kinerja karyawan dan pada sisi lain dapat berpengaruh terhadap daya saing dan kelangsungan hidup perusahaan. Sebagai balas jasa atas kinerja karyawan, perusahaan memberikan kompensasi kepada karyawannya sebagai bukti bahwa perusahaan memperhatikan kesejahteraan karyawannya (Mulyadi, 2015). Hal ini juga sesuai dengan penelitian yang dilakukan oleh (Haditya, Al 
Musadieq, \& Nurtjahjono, 2017) yang berjudul pengaruh kompensasi dan motivasi terhadap kinerja (studi pada karyawan perusahaan daerah (PD) bank perkreditan rakyat (BPR) bank daerah lamongan) dalam penelitiannya didapatkan hasil bahwa kompensasi berpengaruh signifikan terhadap kinerja.

Dari kompensasi yang diberikan perusahaan terhadap karyawannya maka karyawan akan termotivasi untuk melakukan tugas dan tanggung jawab yang sudah diberikan oleh perusahaan, Motivasi kerja karyawan perlu di bangkitkan agar karyawan dapat melaksanakan kinerja yang terbaik, sebaliknya karyawan yang memiliki motivasi rendah dalam melakukan pekerjaannya akan sulit untuk bekerja dengan baik dan cenderung tidak bertanggung jawab sekalipun karyawan tersebut memiliki kemampuan operasional yang baik. Meningkatnya motivasi bisa menghasilnya lebih banyak usaha serta prestasi kerja yang lebih baik (Armstrong, 1990). Hal ini juga sesuai dengan penelitian yang dilakukan oleh Olivia Theodora yang berjudul pengaruh kompensasi terhadap kinerja karyawan PT. Sejahtera motor gemilang, dalam penelitiannya secara parsial dan simultan motivasi exsistence, motivasi relatedness, motivasi growth, mempunyai pengaruh signifikan terhadap kinerja karyawan.

PT Xyz Karawang merupakan salah satu perusahaan modal asing (PMA) yang bergerak di bidang otomotif, perusahaan yang berlokasi di kawasan kota industri Karawang ini memproduksi sekring pada kendaraan bermotor. kegiatan perusahaan ini dikatan cukup padat mulai dari tahapan design awal, tahapan design produk, cara pembuatan dan tahapan pembuatan pada departemen produksi hingga pengiriman produk kepada pelanggan. Perusahaan ini memiliki bebarapa departement di dalamnya seperti human resourch development (HRD) \& general affair (GA), finance \& accounting, quality control dan produksi. Dengan keadaan seperti itu, PT Xyz Karawang memiliki 150 karyawan yang beroperasi pada bagian masing-masing dan dibagi menjadi tiga shift setiap harinya.

Visi dan misi suatu organisasi dapat dicapai jika sumber daya manusianya memiliki kinerja yang baik. Faktor SDM ini merupakan elemen yang harus diperhatikan oleh organisasi, menurut (Umam, 2010) kinerja adalah hasil kerja yang dicapai oleh individu sesuai dengan peran atau tugasnya dalam periode tertentu, yang dihubungkan dengan ukuran nilai atau standar tertentu dari organisasi tempat individu tersebut bekerja. Hal ini juga sesuai dengan penelitian yang dilakukan oleh Ferdy Roring yang berjudul pengaruh kepemimpinan, pembagian kerja dan kompensasi terhadap kinerja karyawan pada PT bank danamon cabang manado, dalam penelitiannya menyebutkan kepemimpinan, pembagian kerja, dan kompensasi secara bersama dan parsial berpengaruh positif dan signifikan terhadap kinerja karyawan.

Kinerja individu sebagai kemampuan individu dalam melakukan sesuatu dengan keahlian tertentu, bahwa kineja diartikan sebagai hasil dari evaluasi terhadapat pekerjaan yang dilakukan individu dibandingkan dengan kriteria yang telah ditetapkan. Berikut ini pencapaian kinerja karyawan PT Xyz Karawang pada tahun 2020: 
Tabel 1

Pencapaian Kinerja Karyawan PT Xyz Karawang Tahun 2020

\begin{tabular}{llll}
\hline Bulan & Target Ideal & Realisasi & Presentasi \\
\hline Jan & 680 & 680 & $100 \%$ \\
\hline Feb & 680 & 680 & $100 \%$ \\
\hline Mar & 680 & 680 & $100 \%$ \\
\hline Apr & 700 & 700 & $100 \%$ \\
\hline Mei & 700 & 700 & $100 \%$ \\
\hline Jun & 700 & 700 & $100 \%$ \\
\hline Jul & 700 & 700 & $100 \%$ \\
\hline Agt & 700 & 700 & $100 \%$ \\
\hline Sep & 700 & 700 & $100 \%$ \\
\hline Okt & 680 & 640 & $94 \%$ \\
\hline Nov & 680 & 657 & $97 \%$ \\
\hline Des & 680 & 633 & $93 \%$ \\
\hline
\end{tabular}

Berdasarkan tabel pencapaian kinerja karyawan PT Xyz Karawang pada tahun 2020 diatas dapat diketahui pada bulan oktober sampai desember kinerja karyawan tidak menurun, artinya karyawan tidak memenuhi target yang sudah ditetapkan oleh perusahaan pada bulan oktober sampai desember 2020, hal ini menunjukan bahwa perusahaan mempunyai kendala khususnya dalam pencapaian kinerja karyawan yang tidak maksimal.

Adapun beberapa informasi mengenai masalah yang terjadi di PT Xyz, diantaranya:

Tabel 2

Hambatan Kinerja pada PT Xyz Karawang

\begin{tabular}{lll}
\hline No & Hambatan & Persentase \\
\hline 1. & $\begin{array}{l}\text { Beberapa karyawan belum bisa mencapai target } \\
\text { yang sudah ditetapkan oleh perusahaan }\end{array}$ & $27 \%$ \\
\hline 2. & $\begin{array}{l}\text { karyawan belum dapat menyelesaikan masalah } \\
\text { ketika terjadi suatu masalah pada pekerjaannya }\end{array}$ & $26 \%$ \\
\hline
\end{tabular}

Sumber: PT Xyz Karawang

Tabel 3

Hambatan Kompensasi pada PT Xyz Karawang

\begin{tabular}{lll}
\hline No & Hambatan & Persentase \\
\hline 1. & $\begin{array}{l}\text { Ketidak sesuaian bonus yang diberikan dari hasil } \\
\text { pekejaan karyawan }\end{array}$ & $25 \%$ \\
\hline 2. & $\begin{array}{l}\text { Fasilitas perusahaan yang diberikan kepada } \\
\text { karyawan oleh perusahaan masih belum dapat } 25 \% \\
\text { menunjang kegiatan kerja karyawan. }\end{array}$ \\
\hline
\end{tabular}

Sumber: PT Xyz Karawang 
Tabel 4

Hambatan Motivasi pada PT Xyz Karawang

\begin{tabular}{llll}
\hline No & Hambatan & Persentase \\
\hline 1. & $\begin{array}{l}\text { Mengukur resiko yang diperoleh artinya } \\
\text { karyawan masih belum mengetahui resiko kerja } \\
\text { bila pekerjaannya kurang sesuai. }\end{array}$ \\
\hline $\begin{array}{l}\text { Melakukan perubahan atau inovasi kreatif } \\
\text { artinya karyawan masih belum mengetahui } 28 \% \\
\text { resiko kerja bila pekerjaannya kurang sesuai }\end{array}$ \\
\hline
\end{tabular}

Sumber: PT Xyz Karawang

Menurut (Malayu S. P. Hasibuan, 2012) Kinerja pegawai didefinisikan kemampuan pegawai dalam melakukan sesuatu keahlian tertentu. Kinerja pegawai sangatlah perlu sebab dengan kinerja ini akan diketahui seberapa jauh kemampuan untuk mereka dalam melaksanakan tugas yang dibebankan kepadanya.

Menurut (Suparyadi, 2015) Kompensasi adalah keseluruhan imbalan yang diterima oleh karyawan sebagai penghargaan atas kontribusi yang diberikannya kepada organisasi, baik yang bersifat finansial maupun nonfinansial.

Menurut American Encyclopedia dalam (M. Idrus Hasibuan, 2014), motivasi adalah kecenderungan (suatu sifat yang merupakan pokok pertentangan) dalam diri seseorang yang membangkitkan dan mengarahkan tindakannya. Motivasi meliputi faktor kebutuhan biologis dan emosional yang hanya dapat diduga dari pengamatan tingkah laku manusia.

Dari ketiga dasar penjelasan diatas kaitannya dengan penelitian ini yaitu ingin menganalisis hubungan yang terjadi antara kompensasi, motivasi dan kinerja karyawan yang ada di PT Xyz Karawang.

\section{Metode Penelitian}

Penelitian ini dilakukan pada PT Xyz Karawang yang terletak di Karawang international industrial city (KIIC), jalan harapan raya lot KK-2C, Sirnabaya, Telukjambe Timur, Karawang, Jawa Barat. Penelitian ini dilakukan pada oktober 2020 sampai november 2020 dengan tahapan penelitian meliputi (1) Prasurvai, (2) Uji Coba Instrumen, (3) Pengumpulan Data, (4) Analisi Data, dan (5) Penulisan Laporan.

Populasi yang digunakan dalam penelitian ini adalah Karyawan PT Xyz, populsai penelitian berjumlah 150 orang, teknik pengambilan sampel yang digunakan dalam penelitian ini adalah simple random sampling dengan menggunakan rumus slovin, yaitu:

$$
\mathrm{n}=\frac{\mathrm{N}}{1+\left(\mathrm{N} \mathrm{x} \mathrm{e}^{2}\right)}
$$

Dimana: $\mathrm{n}=$ Ukuran Sampel

$$
\begin{aligned}
\mathrm{N} & =\text { Populasi } \\
\mathrm{e} & =\text { Tingkat Kesalahan }(5 \%)
\end{aligned}
$$

Maka jumlah sampel yang diambil yaitu: 
Kevin Fewa Morando, Edi Suswardji Nugroho dan Solehudin

$$
\begin{gathered}
n=\frac{150}{1+\left(150 \times 0,05^{2}\right)} \\
n=\frac{150}{1,375} \\
n=109,909 \approx 110
\end{gathered}
$$

Sehingga penelitian ini menggunakan sampel sebanyak 110 orang, peneliti mengumpulan data menggunakan 2 (dua) cara, yaitu menyebarkan kuesioner kepada 110 respnden yang telah disusun. Instrumen penelitian yang digunakan merupakan instrumen yang dikembangkan oleh peneliti sendiri. Peneliti menggunakan skala likert untuk mengetahui masing-masing variabel yaitu variabel $\mathrm{X}_{1}$ (kompensasi), $\mathrm{X}_{2}$ (motivasi) dan variabel Y (kinerja karyawan). Model hubungan antara ketiga variabel penelitian ini dapat digambarkan sebagai berikut:

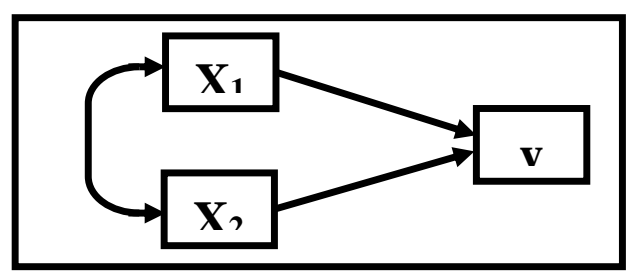

\section{Gambar 1}

\section{Alur Hubungan Antar Variabel Penelitian}

Keterangan:

$\mathrm{X} 1$ = Motivasi

$\mathrm{X} 2$ = Pelatihan dan Pengembangan

$\mathrm{Y}=$ Kinerja

Menurut (Sugiyono, 2017) menuturkan bahwa skala likert digunakan untuk mengukur sikap, pendapat dan persepsi individu/kelompok tentang fenomena sosial. Dalam analisis kuantitatif penelitian ini, maka setiap pertanyaan diberi skala sangat setuju sampai sangat tidak setuju. Skala likert menggunakan 5 (lima) tingkatan jawaban yang dapat dilihat dari tabel berikut:

Tabel 5

Instrumen Skala Likert

\begin{tabular}{clc}
\hline No & \multicolumn{1}{c}{ Pertanyaan } & Skor \\
\hline 1 & Sangat Setuju (SS) & 5 \\
\hline 2 & Setuju (S) & 4 \\
\hline 3 & Kurang Setuju (KS) & 3 \\
\hline 4 & Tidak Setuju (TS) & 2 \\
\hline 5 & Sangat Tidak Setuju (STS) & 1 \\
\hline & Sumber: (Sugiyono, 2017)
\end{tabular}


Cara berikutnya yaitu studi kepustakaan, serta dokumen yang didapat di tempat penelitian. Data yang telah didapat kemudian dikumpulkan, selanjutnya peneliti melakukan uji instrumen. Uji instrumen melalui dua tahap pengujian, uji validitas dan uji realibilitas. Untuk melakukan uji validitas, peneliti menggunakan rumus korelasi product moment pearson. Sedangkan uji realibilitas, penulis menggunakan rumus alpha cronbach sebagai alat ukur. Adapun intrepretasi koefisien korelasi $\mathrm{r}$ sebagai berikut (Sugiyono, 2017):

Tabel 6

Intrepretasi Koefisien Korelasi $\mathbf{r}$

\begin{tabular}{cc}
\hline Interval Koefisien & Tingkat Hubungan \\
\hline $0,80-1,00$ & Sangat Kuat \\
\hline $0,60-0,80$ & Kuat \\
\hline $0,40-0,59$ & Cukup Kuat \\
\hline $0,20-0,39$ & Rendah \\
\hline $0,00-0,19$ & Sangat Rendah \\
\hline
\end{tabular}

Pengujian berikutnya adalah melakukan uji hipotesis atau uji statistik t yang bertujuan agar peneliti mengetahui seberapa besar pengaruh dari variabel indepenen secara individual dalam menjelaskan variasi variabel dependen dan dilanjutkan dengan melakukan uji parmeter secara simultan atau uji F.

\section{Hasil dan Pembahasan}

A. Uji t variabel kompensasi $\left(X_{1}\right)$ dan variabel motivasi $\left(X_{2}\right)$ terhadap variabel kinerja (Y)

Hasil uji t penelitian ini dapat dilihat pada tabel berikut :

Tabel 7

Hasil perhitungan uji t kedua variabel independent

\begin{tabular}{|c|c|c|c|c|c|c|}
\hline \multirow[b]{2}{*}{ Mode } & & \multicolumn{2}{|c|}{$\begin{array}{l}\text { Unstandardized } \\
\text { Coefficients }\end{array}$} & \multirow{2}{*}{$\begin{array}{l}\text { Standardized } \\
\text { Coefficients } \\
\text { Beta }\end{array}$} & \multirow[b]{2}{*}{$\mathrm{t}$} & \multirow[b]{2}{*}{ Sig. } \\
\hline & & B & Std. Error & & & \\
\hline \multirow[t]{3}{*}{1} & (Constant) & 17,266 & 3,654 & & 4,725 &, 000 \\
\hline & $\mathrm{x} 1$ & ,230 & ,081 & ,246 & 2,832 & ,006 \\
\hline & $\mathrm{x} 2$ & ,494 & ,080 & .535 & 6,167 & ,000 \\
\hline
\end{tabular}

Sumber: Hasil olah data menggunakan SPSS 22.0

Dari tabel di atas dapat dijabarkan sebagai berikut:

1. Dari hasil uji $\mathrm{t}$ menggunakan SPSS didapatkan nilai $t_{\text {hitung }}$ untuk variabel Kompensasi $\left(\mathrm{X}_{1}\right)$ terhadap variabel kinerja $(\mathrm{Y})$ sebesar 2,832 dan $\mathrm{t}_{\text {tabel }}$ sebesar 1,65882, maka 2,832>1,65882 sehingga dapa disimpulkan bahwa variabel kompensasi $\left(\mathrm{X}_{1}\right)$ mempunyai pengaruh yang positif dan signifikan terhadap variabel Kinerja (Y). 
2. Dari hasil uji $\mathrm{t}$ menggunakan SPSS didapatkan nilai thitung untuk variabel Motivasi $\left(\mathrm{X}_{2}\right)$ terhadap variabel kinerja $(\mathrm{Y})$ sebesar 6,167 dan $\mathrm{t}_{\text {tabel }}$ sebesar 1,65882, maka 6,167 > 1,65882 sehingga dapa disimpulkan bahwa variabel Motivasi $\left(\mathrm{X}_{2}\right)$ mempunyai pengaruh yang positif dan signifikan terhadap variabel Kinerja (Y).

B. Uji F antara variabel kompensasi dan variabel motivasi secara simultan terhadap variabel kinerja

Hasil uji F penelitian ini dapat dilihat pada tabel berikut:

\section{Tabel 8}

Uji Simultan (Uji F) ANOVA ${ }^{a}$

\begin{tabular}{llllllr}
\hline & Model & Sum of Squares & Df & Mean Square & F & Sig. \\
\hline \multirow{1}{*}{1} & Regression & 3400,263 & 2 & 1700,131 & 55,860 &, $000^{\mathrm{b}}$ \\
\cline { 2 - 7 } & Residual & 3256,610 & 107 & 30,436 & & \\
\cline { 2 - 6 } & Total & 6656,873 & 109 & & & \\
\hline
\end{tabular}

Sumber: Hasil olah data menggunakan SPSS 22.0

Dari tabel diatas diketahui bahwa $F_{\text {hitung }}$ adalah 55,860. Nilai $F_{\text {tabel }}$ dengan sampel sebanyak 110 dan dua variabel bebas adalah 3,08. Perbandingan antara $F_{\text {tabel }}$ dan $\mathrm{F}_{\text {hitung }}$ adalah 55,860 $>3,08$, maka dapat disimpulkan terdapat pengaruh yang positif dan signifikan antara variabel kompensasi $\left(\mathrm{X}_{1}\right)$ dan motivasi $\left(\mathrm{X}_{2}\right)$ secara bersama-sama atau simultan terhadap variabel kinerja $(\mathrm{Y})$.

C. Koefisien Determinasi

Nilai koefisien determinasi penelitian dapat dilihat pada tabel berikut:

Tabel 9

Koefisien Determinasi

\begin{tabular}{lcccc}
\hline Model & $\mathrm{R}$ & $\mathrm{R}$ Square & $\begin{array}{c}\text { Adjusted R } \\
\text { Square }\end{array}$ & $\begin{array}{c}\text { Std. Error of the } \\
\text { Estimate }\end{array}$ \\
\hline 1 &, $715^{\mathrm{a}}$ &, 511 &, 502 & 5,517 \\
\hline Sumber: Hasil olah data menggunakan SPSS 22.0 & \\
\hline
\end{tabular}

Berdasarkan tabel diatas didapatkan nilai $\mathrm{R}$ square sebesar 0,511 yang artinya variabel kompensasi dan variabel motivasi secara bersama-sama mampu menjelaskan variabel kinerja sebesar $51,1 \%$ sedangkan, sisanya sebesar 48,9\% merupakan faktor-faktor lain yang tidak diteliti dalam penelitian ini.

D. Analisis Regresi Linear Berganda

Berdasarkan Hasil perhitungan uji $\mathrm{t}$ kedua variabel independent didapat persamaan regresi linear berganda sebagai berikut:

$\mathrm{Y}=17,266+0,230 \mathrm{X}_{1}+0,494 \mathrm{X}_{2}$

Dimana:

$\left(\mathrm{X}_{1}\right)=$ Kompensasi

$\left(\mathrm{X}_{2}\right)=$ Motivasi

$\mathrm{Y}=$ Kinerja

Penjelasannya sebagai berikut: 
1. Nilai konstanta (koefisien intersep) yang diperoleh dari hasil perhitungan uji $t$ kedua variabel independent adalah sebesar 17,266. Hal ini menyatakan jika variabel kompensasi $\left(\mathrm{X}_{1}\right)$ dan variabel motivasi $\left(\mathrm{X}_{2}\right)$ nol maka nilai variabel Kinerja (Y) sebesar 17,266.

2. Nilai koefisien regresi variabel kompensasi $\left(\mathrm{X}_{1}\right)$ terhadap variabel kinerja $(\mathrm{Y})$ adalah sebesar 0,230. Hal ini menjelaskan jika variabel kompensasi $\left(\mathrm{X}_{1}\right)$ naik sebesar 1\%, akan meningkatkan variabel kinerja (Y) sebesar 0,230, dengan asumsi variabel motivasi $\left(\mathrm{X}_{2}\right)$ dan konstanta dianggap tetap. Artinya jika kompensasi yang diterima karyawan sesuai baik itu finansial atau non finansial oleh perusahaan maka akan memberikan hasil positif bagi kinerja karyawan tersebut. Dilihat dari hasil angket yang sudah disebarkan kepada 110 responden menunjukan bahwa motivasi karyawan berada pada skala baik. Hal ini juga sepaham dengan yang dikutip dari (Malayu S. P. Hasibuan, 2012) menurut Sastrohadiwiryo (2015) mengatakan bahwa kompensasi adalah imbalan jasa atau balas jasa yang diberikan oleh organisasi kepada para tenaga kerja karena tenaga kerja tersebeut telah memberikan sumbangan tenaga dan pemikiran demi kemajuan organisasi guna mencapai tujuan yang telah ditetapkan. Hal ini juga sepaham dengan penelitian yang dilakukan oleh (Dwianto, Purnamasari, \& Tukini, 2019) dengan judul pengaruh kompensasi terhadap kinerja karyawan pada PT. JAEIL Indonesia, dalam penelitiannya menyebutkan bahwa presentase kompensasi mempengaruhi kinerja karyawan bagian produksi PT. JAEIL Indonesia kompensasi dapat memberikan kontribusi sebesar $48,6 \%$ terhadap kinerja karyawan dan sisanya sebesar $51,4 \%$ dipengaruhi oleh variabel lain yang tidak dimasukkan kedalam penelitian.

3. Nilai koefisien regresi variabel Motivasi $\left(\mathrm{X}_{2}\right)$ terhadap variabel kinerja $(\mathrm{Y})$ adalah sebesar 0,494. Hal ini menjelaskan jika variabel motivasi $\left(\mathrm{X}_{2}\right)$ naik sebesar 1\%, akan meningkatkan variabel kinerja (Y) sebesar 0,494, dengan asumsi variabel kompensasi $\left(\mathrm{X}_{1}\right)$ dianggap konstan atau tidak berubah. Artinya jika motivasi karyawan dalam bekerja terus meningkat akan memberikan dampak yang positif bagi tugas atau pekerjaan yang sudah diberikan oleh perusahaan. Dilihat dari hasil angket yang sudah disebarkan kepada 110 responden menunjukan bahwa motivasi karyawan berada pada skala baik. Hal ini juga sepaham dengan yang dikutip dalam (Suparyadi, 2015) menurut (Churchwell et al., 2006) mengatakan motivasi sebagai hasrat didalam diri sesorang yang menyebabkan seseorang melakukan suatu tindakan. Penelitian ini juga sejalan dengan penelitian yang dilakukan oleh (Kasenda, 2013) dengan judul kompensasi dan motivasi pengaruhnya terhadap kinerja karyawan pada PT. Bangun wenang beverages company manado. Dalam penelitiannya menyebutkan bahwa motivasi berpengaruh signifikan terhadap kinerja karyawan PT. Bangun Wenang beverages company manado. Dalam jurnal yang ditulis oleh (Andico \& Hadi, 2013) menyimpulkan bahwa Motivasi kerja berpengaruh 
dan signifikan terhadap kinerja karyawan dimana t-hitung sebesar 7,243 yang berarti hubungan keduanya sangat kuat.

\section{Kesimpulan}

Berdasarkan hasil penelitian menunjukkan adanya pengaruh positif dan signifikan antara kompensasi terhadap kinerja karyawan, jika kompensasi yang diterima karyawan sesuai baik itu finansial atau non finansial oleh perusahaan maka akan memberikan hasil positif bagi kinerja karyawan tersebut.

Hal yang sama juga terdapat pada variabel motivasi terhadap variabel kinerja. Jika motivasi karyawan dalam bekerja terus meningkat akan memberikan dampak yang positif bagi tugas atau pekerjaan yang sudah diberikan oleh perusahaan.

Berdasarkan hasil dari perhitungan analisis regresi linier berganda menunjukkan bahwa variabel motivasi lebih dominan pengaruhnya terhadap variabel kinerja karyawan. Sehingga perusahaan sebaiknya lebih memberikan perhatian lebih berupa motivasi yang membangun kepada karyawan. Karena motivasi merupakan upaya meningkatkan kinerja karyawan yang akan berdampak pada kinerja perusahaan. 


\section{BIBLIOGRAFI}

Andico, Christian, \& Hadi, Sudharto Prawoto. (2013). Pengaruh Kompensasi dan Motivasi Kerja Terhadap Kinerja Karyawan PT. Pelabuhan Indonesia III (Persero) Terminal Peti Kemas Semarang. Jurnal Ilmu Administrasi Bisnis, 2(4), 146-154.

Armstrong, Michael. (1990). Manajemen Sumber Daya Manusia, terjemahan Sofyan dan Haryanto, Jakarta: PT. Elex Media Komputindo.

Churchwell, E., Povich, M. S., Allen, D., Taylor, M. G., Meade, M. R., Babler, B. L., Indebetouw, R., Watson, C., Whitney, B. A., \& Wolfire, M. G. (2006). The bubbling galactic disk. The Astrophysical Journal, 649(2), 759.

Dwianto, Agung Surya, Purnamasari, Pupung, \& Tukini, Tukini. (2019). Pengaruh Kompensasi Terhadap Kinerja Karyawan Pada PT. JAEIL INDONESIA. Jesya (Jurnal Ekonomi Dan Ekonomi Syariah), 2(2), 209-223.

Haditya, Rizki Akbar, Al Musadieq, Mochammad, \& Nurtjahjono, Gunawan Eko. (2017). Pengaruh Kompensasi dan Motivasi Terhadap Kinerja (Studi Pada Karyawan Perusahaan Daerah (PD) Bank Perkreditan Rakyat (BPR) Bank Daerah Lamongan). Jurnal Administrasi Bisnis, 51(1), 145-150.

Hasibuan, M. Idrus. (2014). Model Pembelajaran CTL (Contextual Teaching and Learning). Logaritma: Jurnal Ilmu-Ilmu Pendidikan Dan Sains, 2(01).

Hasibuan, Malayu S. P. (2012). Manajemen sumber daya manusia Jakarta: Bumi Aksara.

Kasenda, Ririvega. (2013). Kompensasi dan motivasi pengaruhnya terhadap kinerja karyawan pada PT. Bangun Wenang Beverages Company Manado. Jurnal EMBA: Jurnal Riset Ekonomi, Manajemen, Bisnis Dan Akuntansi, 1(3).

Mulyadi. (2015). Manajemen Sumber Daya Manusia.

Sugiyono, P. Dr. (2017). Metode Penelitian Pendidikan: Pendekatan Kuantitatif, Kualitatif, R\&D (Cetakan Ke), Bandung: CV Alfabeta.

Suparyadi, H. (2015). Manajemen Sumber Daya Manusia.

Umam, Khaerul. (2010). Perilaku Organisasi, Edisi I, Bandung: CV. Pustaka Setia. 